\title{
TEORÍA DEL DERECHO, NEOCONSTITUCIONALISMO Y MODELO DE ESTADO CONSTITUCIONAL EN EL CONTEXTO COLOMBIANO
}

\author{
Nicole Velasco Cano \\ Jairo Vladimir Llano \\ Universidad Libre SECCIONAL CALi \\ Universidad Cooperativa de Colombia seccional Cali
}

\section{Resumen}

El modelo de Estado constitucional y democrático de Derecho se soporta en la teoría neoconstitucionalista y desarrolla elementos particulares y característicos que proponen innovadoras ideas frente a la estructura estatal, entre ellos, la supremacía constitucional, el control de constitucionalidad, la protección y garantía de los derechos y el papel activo del juez como creador de Derecho. En el contexto colombiano, no ha alcanzado sus pretensiones, ya que este modelo fue trasplantado de Europa y, por lo tanto, la realidad sociojurídica es diferente; esto deriva consecuencias negativas en su implementación. En este artículo también se reflexionará sobre las propuestas teóricas que se han desarrollado como crítica a los postulados del neoconstitucionalismo: el constitucionalismo popular como una propuesta teórica proveniente de Estados Unidos y el nuevo constitucionalismo que está consolidándose en América Latina. Estas dos propuestas tienen como eje un mayor activismo por parte de los sectores sociales y el control de constitucionalidad ejercido por la ciudadanía.

Palabras clave: neoconstitucionalismo, Estado constitucional, Constitución, garantía de derechos, control de constitucionalidad.

\section{Los autores:}

Nicole Velasco Cano es abogada, investigadora independiente en el área de teoría del Derecho y modelos de Estado. Correo electrónico: nicolcilla13@hotmail.com

Jairo Vladimir Llano es doctor en Derecho, antropólogo especialista en Antropología Jurídica, becario del Instituto de Sociología Jurídica de Oñati (España). Profesor de la Universidad Libre, seccional Cali. Correo electrónico: jairoderecho1@hotmail.com

Recibido: 14 de julio de 2015; evaluado: 21 de agosto de 2015; aceptado: 21 de septiembre de 2015. 


\title{
LEGAL THEORY, NEOCONSTITUTIONALISM AND CONSTITUTIONAL STATE MODEL IN THE COLOMBIAN CONTEXT
}

\author{
Nicole Velasco Cano \\ Jairo Vladimir Llano \\ UNIVERSIDAD LibRe SECCIONAL CALI \\ Universidad Cooperativa de Colombia seccional Cali
}

\begin{abstract}
The model of constitutional and democratic state of Law is supported by the neoconstitutionalist theory and develops individual and characteristic elements that propose innovative ideas in front of the state structure, including the constitutional supremacy, judicial review, protection and guarantee of rights and the active role of the judge as a creator of Law. In the Colombian context, it has not achieved its claims, since this model was transplanted from Europe and, therefore, social and legal reality is different; this results as negative consequences in its implementation. This article will also reflect on the theoretical proposals that have been developed as a critique of the postulates of neoconstitutionalism: popular constitutionalism, -as a theoretical proposal from the United States and the new constitutionalism that is consolidating in Latin America. These two proposals have centered around an increased activism on the part of the social sectors and the judicial review exercised by the public.
\end{abstract}

Keywords: neoconstitutionalism, constitutional State, Constitution, guaranteeing rights, constitutional review.

\section{About the authors:}

Nicole Velasco Cano: Lawyer, independent researcher in the area of Theory of Law and State Models. Email: nicolcilla13@hotmail.com

Jairo Vladimir Llano: Doctor of Law, anthropologist specializing in Legal Anthropology, scholarship holder of the Institute of Sociology of Law in Oñati (Spain). Professor at the Libre University based in Cali. Email: jairoderechol@hotmail.com

Received: July 14, 2015; reviewed: August 21, 2015; accepted: September 21, 2015. 


\section{Introducción}

Entre los debates recientes de la Ciencia Jurídica se encuentra aquel sobre los modelos de Estado desde una perspectiva de la teoría del Estado, pero sin abandonar el concepto de Derecho como un eje complementario de los distintos esquemas implementados en la Modernidad.

El primer modelo de Estado que estaba a tono con la consolidación de la Modernidad y del Estado Nación es el legislativo de Derecho, en el que la creación de la ley y su obediencia por parte de los ciudadanos era el objetivo central. Más adelante, en el siglo XX, apareció el Estado social de Derecho, cuya pretensión central era la garantía de los derechos sociales fundamentales de los ciudadanos de los Estados contemporáneos. A finales del siglo XX surgieron tanto el Estado constitucional y democrático de Derecho - que busca proteger la totalidad de los derechos fundamentales ante las dinámicas del mercado- como su opuesto, el Estado de Derecho neoliberal, que tiene su mayor soporte en el mercado y la libertad de competencia.

Estos esquemas estatales han sido trasplantados a América Latina, pero no se implementaron a plenitud, debido a las condiciones socioeconómicas y culturales que caracterizan a la región; por el contrario, los resultados han sido negativos para los ciudadanos de estos Estados y, por eso, emerge la necesidad de replantear los modelos de Estado se adecúan a la realidad latinoamericana.

En su primera parte, el presente artículo expone las características del Estado constitucional y democrático de Derecho. En la segunda sección, se reflexiona sobre los antecedentes teóricos del Estado constitucional y democrático de Derecho expuestos por Kelsen y Hart. En tercer lugar, se analiza la implementación del modelo de Estado constitucional en América Latina y en Colombia. En la cuarta sección se aborda el neoconstitucionalismo como el enfoque teórico que soporta el modelo de Estado constitucional y democrático de Derecho y, por último, se revisan la influencia y los obstáculos del Estado constitucional en un contexto complejo como el colombiano.

\section{Distinciones del Estado constitucional y democrático de Derecho}

La Constitución es el pilar del Estado constitucional y esta es una de las características que lo diferencian de modelos estatales anteriores. Se puede observar que, 
en el Estado legislativo, las Constituciones no eran vinculantes ni superiores a la legislación ordinaria y esto hacía que el Poder Legislativo tuviera supremacía frente a la Constitución. Caso contrario ocurre con el reciente modelo de Estado constitucional, en el que la Constitución es el eje del ordenamiento jurídico interno. Aparece la supremacía constitucional y supedita a todos los poderes del Estado, que serán controlados por los intérpretes (jueces) y las acciones constitucionales:

El paso del Estado legislativo al constitucional presupone la afirmación del carácter normativo de las constituciones, que pasarán a integrar un plano de juridicidad superior, vinculante e indisponible, en línea de principio, para todos los poderes del Estado. Las normas constitucionales son vinculantes — de modo que queda definitivamente superada la imagen débil de la juridicidad constitucional característica del periodo liberal — al ser situadas por encima de los poderes del Estado y fuera del campo de acción y pugna política. De este modo, los poderes públicos no pueden disponer del sentido y contenido de las normas constitucionales - al menos en condiciones de normalidad general—y, precisamente por ello, del propio Derecho como realidad constituida. ${ }^{1}$

En la Contemporaneidad, los modelos de Estado que se han venido desarrollando pretendieron considerar las necesidades de los asociados, al impulsar y promover la relación de Estado-sociedad y Derecho-Estado. Estas pretensiones se han incorporado a la idea de un nuevo modelo de Estado. Desde el Derecho Constitucional reciente y la Filosofía del Derecho contemporánea, a este modelo se le reconoce como Estado constitucional y democrático de Derecho, cuyas características, señaladas por estas especialidades de la Ciencia Jurídica, son: primero, la garantía de los derechos fundamentales de los ciudadanos:

Entre los objetos de la garantía, uno de los principales elementos a través de los que se hace efectiva en el ordenamiento esta función son los derechos fundamentales reconocidos constitucionalmente: su peculiar vínculo con los valores externos, su situación en el contexto constitucional y sus garantías jurisdiccionales o institucionales, los convierten en un factor jurídico de primer orden y en el elemento jurídico más potencialmente garantista de los presentes en el ordenamiento. ${ }^{2}$

Antonio Peña Freire, La garantía en el Estado constitucional de Derecho (Madrid: Trotta, 1997), 59

Peña Freire, La garantía en el Estado constitucional de Derecho, 107-108. 
La segunda es la supremacía constitucional respecto al ordenamiento jurídico:

[...] ello supone necesariamente que el régimen jurídico de las disposiciones constitucionales es diferente del de las disposiciones legales y superiores a ellas. Por tanto, desde la perspectiva interna de la doctrina de las fuentes del Derecho, los Estados constitucionales se caracterizan por contar con una Constitución formal y ello implica siempre — como mínimo- una diferencia de grado ante las otras fuentes del Derecho. ${ }^{3}$

Otro rasgo de este interesante modelo estatal es que la Constitución pretende la inclusión de los sectores sociales, los comportamientos y las dinámicas colectivas que históricamente fueron excluidas:

Más que una magnitud dada por anticipación de manera ligada a la naturaleza, el pueblo es una magnitud cultural pluralista que se configura en la Constitución propia de los Estados constitucionales y se renueva constantemente en sus relaciones interculturales. Se compone de portadores de derechos fundamentales, esto es, de ciudadanos. De ellos proviene, en últimas, todo poder (estatal). ${ }^{4}$

En cuanto a la innovación del modelo de Estado constitucional:

[... ] no nos referimos (sólo) a una realidad política precisa, a un orden jurídicopolítico real o positivo o a un conglomerado institucional determinado, sino más bien a un modelo normativo general que va más allá de configuraciones normativas o realidades positivas empíricamente verificables sin desconocerlas. ${ }^{5}$

La transformación jurídico-política que aporta el modelo constitucional a la construcción de una nueva forma de Estado está ligada al bienestar del ser humano y su protección, ya que, en el Estado constitucional, los derechos fundamentales no solo son vinculantes desde la Constitución, sino también desde el Derecho Internacional, con la pretensión de que las personas puedan cumplir con su objetivo de lograr una vida aceptable, lo cual es posible con el cumplimiento de estos derechos:

La equivalencia entre "persona" y "ser humano" y la consiguiente correlación entre "igualdad en los derechos" y "persona humana" se han afirmado, sin

Josep Aguiló, La Constitución del Estado constitucional (Bogotá: Temis, 2004), 51.

Peter Haberle, Constitución como cultura (Bogotá: Universidad Externado de Colombia, 2002), 27.

Peña Freire, La garantía en el Estado constitucional de Derecho, 38. 
embargo, no solo en el plano axiológico, sino también en el plano del Derecho positivo, con el reconocimiento del status de "persona" a todos los seres humanos, producido con las primeras codificaciones y con la configuración, en las constituciones modernas, de casi todos los derechos fundamentales — desde los derechos de libertad a los derechos civiles, hasta gran parte de los derechos sociales - como "derechos de las personas", y solo de los derechos políticos y de algunos derechos sociales como "derechos del ciudadano". 6

\section{La implementación del Estado constitucional en América Latina y Colombia}

En el contexto de América Latina la adopción del modelo de Estado constitucional ha sido complejo y se ha incorporado paulatinamente por medio de nuevas Constituciones o reformas a las mismas, que determinan la supremacía constitucional con la protección de la Carta y los derechos fundamentales mediante un órgano especializado, como denominaría Kelsen al Tribunal Constitucional:

Desde comienzos de los años noventa se han expedido nuevas constituciones en la mayoría de los Estados latinoamericanos o se han introducido profundas reformas a las constituciones existentes [...] el rasgo básico de este tipo de Estado es el principio de supremacía de la Constitución. En realidad, este principio no es una novedad en el contexto latinoamericano, sino que se trasplantó al subcontinente a partir de la segunda década del siglo XIX [... el el principio de constitucionalidad no habrá implicado una transformación radical en el constitucionalismo en América Latina de no ser porque, en esta última era, ha sido acompañado por la proclamación de derechos fundamentales en la Constitución y la atribución de su protección a tribunales constitucionales especializados (como en el caso de Colombia, Perú y Ecuador) o a las tradicionales Cortes Supremas de Justicia (como en el caso de Argentina y, en parte, México, en donde a la protección que ofrece la Corte Suprema a estos derechos se suma la que brinda el Tribunal Electoral del Poder Judicial de la Federación). Es esta, por tanto, la verdadera novedad y la característica principal del actual constitucionalismo o, mejor, neoconstitucionalismo, en América Latina. ${ }^{7}$

Luigi Ferrajoli, Los fundamentos de los derechos fundamentales (Madrid: Trotta, 2005), 334.

Carlos Bernal Pulido, "Derechos fundamentales, juristocracia constitucional e hiperpresidencialismo en América Latina" en Justica constitucional, derechos humanos y democracia en América Latina, dir. Arnaud Martin (Bogotá: Universidad Externado de Colombia, 2014), 31-32. 
En la estructura jurídica de los Estados latinoamericanos, se encuentra un órgano encargado de proteger a la Constitución ante las decisiones de los poderes políticos representados en el Ejecutivo y el Legislativo. A este se le conoce como Tribunal o Corte Constitucional y, entre sus funciones, está la realización de acciones jurídicas de carácter constitucional como la revisión de decretos-ley del Ejecutivo y de leyes del Legislativo. Estas decisiones son conocidas por los constitucionalistas y teóricos del derecho contemporáneos como control constitucional o de constitucionalidad, cuya pretensión es evitar el abuso por parte de las organizaciones políticas del Estado sobre los ciudadanos: "El control de constitucionalidad se ha instituido entonces como mecanismo de protección de los derechos fundamentales y de los pilares del Estado, que busca impedir los desafueros de los gobiernos de turno, especialmente en tiempos de crisis". 8

El control de constitucionalidad es ejercido por la Corte o el Tribunal, de acuerdo con la Constitución, ya que se considera a esta organización estatal como la única que cuenta con independencia "política". Este control se soporta en parámetros jurídicos:

El déficit de control político por parte del Congreso se ha intentado suplir con un activismo acentuado por parte de la jurisdicción, sobre todo de la jurisdicción constitucional. De este modo, con fundamento en el principio de constitucionalidad, las cortes constitucionales han intentado controlar el ejercicio excesivo de los poderes presidenciales, han intentado llenar el vacío de control político con una extensión de su control jurídico. En este sentido una de las transformaciones más extraordinarias que han sufrido los Estados latinoamericanos durante la transición a la democracia ha sido la expansión del control de constitucionalidad y la institución de cortes constitucionales para proteger los derechos fundamentales. ${ }^{9}$

El control político y de protección que hace el Poder Judicial lo convierte en uno de los principales protagonistas en la estructura jurídica del Estado constitucional, pues el juez constitucional, con sus decisiones, controla aquellas instituciones públicas responsables de llevar a buen término los postulados constitucionales. Varias de estas decisiones configuran lo que se ha llamado creación del Derecho:

\footnotetext{
Bernal Pulido, "Derechos fundamentales, juristocracia constitucional", 40.

Bernal Pulido, "Derechos fundamentales, juristocracia constitucional", 38-39.
} 
Para que sea viable, el modelo exige una amplia delegación a los jueces constitucionales. Según la constitución clásica de "soberanía legislativa" (hoy prácticamente difunta), se puede considerar a las cortes como agentes (o esclavos) de la legislatura. Sin embargo, el marco básico de agente-principal pierde relevancia cuando se llega a los sistemas modernos de justicia constitucional. [...] el constitucionalismo moderno se caracteriza por la supremacía judicial estructural, en la cual los principales actores políticos transfieren, de hecho, un conjunto significativo de "derechos políticos de propiedad" a los jueces, con una duración indefinida. ${ }^{10}$

Para el caso colombiano, el modelo de Estado constitucional está plasmado en la Constitución de 1991, con la vinculación de derechos fundamentales que son reconocidos en el transcurso del texto constitucional. La creación de la Corte Constitucional, como institución responsable de interpretar la Constitución, es central en la estructura jurídica colombiana, ya que entre sus funciones está el control jurídico-político al Ejecutivo y al Legislativo. Los jueces, en conjunto, son reconocidos como constitucionales, por las funciones jurídicas que les otorga el texto constitucional para proteger derechos fundamentales:

El artículo 4 es la condición de posibilidad de aplicación normativa de toda la Constitución, del ejercicio del control constitucional, [...] la vigencia del Estado constitucional democrático, es decir, del hecho de ser realmente regido por una Constitución. Adicionalmente, el artículo 4 dispone afirmar a las normas constitucionales como las supremas del ordenamiento, desde las que se derivan la validez, la vigencia y la exigibilidad de los demás componentes del sistema normativo, con exclusión de todas aquellas que se opongan a los mandatos constitucionales. ${ }^{11}$

La Corte Constitucional colombiana ha velado por la protección y garantía de derechos fundamentales que tienen los titulares (ciudadanos) y ha ejercido el control de constitucionalidad sobre las organizaciones e instituciones políticas. En varias ocasiones se ha pronunciado sobre políticas gubernamentales que pretenden beneficios particulares que estarían en contravía de los postulados constitucionales,

10 Alec Stone Sweet y Jud Matthews, Proporcionalidad y constitucionalismo. Un enfoque comparativo global (Bogotá: Universidad Externado de Colombia, 2013), 34-35.

11 Manuel Fernando Quince Ramírez, Derecho constitucional colombiano de la Carta de 1991 y sus reformas (Bogotá: Universidad del Rosario, 2009), 97. 
lo que demuestra que la Corte cumple con sus funciones e, incluso, las supera, en un contexto convulsionado y desigual como es el colombiano:

El control de constitucionalidad dirigido a proteger los derechos fundamentales, que en principio fue ideado como un control jurídico objetivo y de carácter negativo, fundado en técnicas interpretativas elaboradas por la metodología constitucional y la dogmática de los derechos fundamentales, se ha transformado en un control con claros tintes políticos, en el que ya no se discute acerca del contraste entre la ley y la Constitución, sino sobre la conveniencia o coherencia de ciertas políticas públicas. En esta dirección, incluso la Corte Constitucional se ha atribuido el control no solo formal sino también material de los actos de reforma de la Constitución, cuando estos han sido propuestos por el gobierno y llevados a cabo por el Congreso en funciones de constituyente secundario. Un relevante ejemplo de este tipo de control es aquel que ejerció la Corte Constitucional colombiana a comienzos del año 2010, sobre el acto de reforma de la Constitución que estaba destinado a permitir la segunda reelección del presidente ÁLVARO URIBE VELEZ. ${ }^{12}$

En algunas ocasiones, la protección de derechos fundamentales se ha visto restringida por parte del Alto Tribunal cuando existen intereses económicos en juego o intervenciones de desarrollo para ciertas regiones, relacionados con los parlamentarios o los miembros del Ejecutivo. Esto se convierte en una de las problemáticas que enfrenta al momento de ejercer un control de constitucionalidad pertinente sobre el Parlamento o el Ejecutivo, pues los magistrados que conforman el Alto Tribunal son elegidos por el Congreso, situación que está en contravía de lo que propone el modelo de Estado constitucional y democrático de Derecho y que podría configurar una especie de crisis de este modelo estatal.

\section{El neopositivismo jurídico como antecedente del Estado constitucional}

La teoría neopositivista se considera la primera en plantear la importancia del juez en la interpretación constitucional y del control de constitucionalidad de los jueces sobre el Parlamento y el Ejecutivo. Entre los teóricos del Derecho, del Derecho Constitucional y de la Filosofía del Derecho que propusieron transformaciones

12 Bernal Pulido, "Derechos fundamentales, juristocracia constitucional", 41. 
jurídicas y de la estructura estatal, se encuentran los neopositivistas jurídicos Hans Kelsen y Hebert Hart. El primero postuló que los poderes políticos deben estar bajo constante control por parte de los jueces constitucionales, debido a que el legítimo intérprete de la Constitución es el juez, quien orienta el quehacer de las instituciones estatales desde una perspectiva constitucional:

La función política de la Constitución —afirma el autor—es la de poner límites jurídicos al ejercicio del poder, y garantía de la Constitución significa certeza de que estos límites no serán rebasados, por ello, ningún órgano es menos idóneo para cumplir con la tarea de custodiar a la Constitución que aquel que tienen el poder político para poder violarla. De esta manera, el principio de que "nadie puede ser juez en su propia causa" es el que lleva a Kelsen a proponer como garante de la Constitución a un órgano ajeno a la aplicación cotidiana de esta. El Parlamento y el gobierno, en cuanto son órganos que participan en la tarea legislativa [...] la naturaleza del control de constitucionalidad es justificada por Kelsen, además, con base en su convicción de que la interpretación de la Constitución es una tarea estrictamente jurídica y, por esa razón, debe ser confiada a técnicos del derecho, como es el caso de los jueces. ${ }^{13}$

Estos postulados de Kelsen fueron interpretados y aceptados en los últimos años por parte de la Ciencia Jurídica y la teoría del Derecho en América Latina. Sus propuestas teóricas fueron interpretadas equivocadamente durante varias décadas; por eso, la propuesta kelseniana de supremacía de la Constitución, de control de constitucionalidad, del juez como intérprete legítimo de la Constitución y de las relaciones del Derecho Constitucional o estatal con el Derecho Internacional están siendo incorporadas por parte de los teóricos, juristas y las mismas instituciones estatales en los procesos de transformación constitucional que se han hecho en los últimos años en la región. Es un verdadero cambio de pensamiento jurídico que ha llevado a una aceptable interpretación de la teoría del Derecho de Hans Kelsen:

El nuevo Derecho se construye a través de una renovada versión de la teoría de Kelsen [...] la transición al antiformalismo contemporáneo en Latinoamérica está marcada por un uso relativamente tardío de la obra de Kelsen destinado a corregir la comprensión pop de su teoría en obras como el "Derecho Civil" de Valencia Zea. Tal como se ha visto, Valencia empleó a Kelsen para generar

13 Lorenzo Córdova Vianello, Derecho y poder: Kelsen y Schmitt frente a frente (México D. F.: Universidad Nacional Autónoma de México, 2009), 281. 
continuidad entre las viejas corrientes dominantes en el clasicismo (el comentario exegético y el conceptualismo) y la entonces novedosa Teoría Pura del Derecho. De esta forma, la recepción de Kelsen no implicó para Valencia una crítica a lo ya existente (como sí lo fue en su momento el impacto del antiformalismo social): la nueva presentación del positivismo podía ser interpretada como un esfuerzo de continuación y consolidación de la conciencia jurídica clásica [...] bajo esta nueva luz, Kelsen no operaba como una ratificación de la teoría clásica del Derecho sino que, por el contrario, colisionaba con ella en varios puntos centrales. Los primeros traductores de Kelsen al español, Legaz y Recasens, habían supuesto equivocadamente que la Reine rechtslehre generaría en la teoría local del Derecho un movimiento crítico frente a lo ya existente. Para ellos, el efecto neto de los argumentos de Kelsen sería, no el de continuación y consolidación de la teoría clásica del Derecho, sino el de crisis y radical modernización de un discurso teórico que se mantenía todavía en las brumas de conceptos muy oscuros e imprecisos. ${ }^{14}$

En los tiempos recientes, los postulados de Hans Kelsen han sido recogidos por los ordenamientos jurídicos estatales con soporte en la Constitución, la cual es el parámetro de creación de normas inferiores, leyes o reglamentos. Esta nueva interpretación ha traído consigo propuestas innovadoras para la conformación de la estructura jurídica:

De esta manera, la llamada "garantía de la Constitución" está finalizada, según Hans Kelsen, a preservar la "regularidad" del ordenamiento, a través de la tarea de verificar la correspondencia entre las leyes y la Constitución e, indirectamente, de todas las normas inferiores con esta última. La función de la garantía de la Constitución es, en pocas palabras, la de mantener la coherencia formal y sustancial del ordenamiento jurídico en su conjunto, anulando, para ello, todas las normas y actos juzgados como inconstitucionales. ${ }^{15}$

A partir de la teoría del Derecho de Kelsen, la importancia de la Constitución y del juez, como su intérprete legítimo, fue recogida por varios autores y adecuada a los postulados que estos tenían sobre el Derecho y su práctica. Es el caso de Hebert Hart, para quien los jueces son esenciales en la interpretación constitucional. Esta postura fue sostenida desde su propuesta de las reglas, divididas en primarias y

14 Diego Eduardo López Medina, Teoría impura del Derecho. La transformación de la cultura jurídica latinoamericana (Bogotá: Universidad de los Andes, 2004), 417.

15 López Medina, Teoría impura del Derecho, 277. 
secundarias. La regla secundaria (constitucional) es determinante para que las reglas primarias puedan existir, pues revisa que las reglas primarias no estén en contra del ordenamiento o sistema jurídico. Hart la llamó regla secundaria de reconocimiento:

Hart establece dos distinciones fundamentales: de un lado, la distinción entre reglas primarias y secundarias [...] las reglas secundarias entre tanto, otorgan potestades a los particulares o a las autoridades públicas para crear, modificar, extinguir, o determinar los efectos de las reglas de tipo primario [...]. Otros ejemplos de reglas secundarias son las normas constitucionales sobre la expedición de leyes y las normas procesales que regulan la función judicial. En el ejercicio de las potestades atribuidas por esas reglas secundarias, los legisladores y los jueces establecen reglas primarias contenidas en leyes y sentencias, respectivamente. Hart llama "reglas de cambio" a las reglas secundarias que dan facultades a los particulares y a los legisladores para crear reglas primarias. Las normas sobre el ejercicio de la función judicial constituye un segundo tipo de reglas secundarias, que Hart denomina "reglas de adjudicación" [...]. La validez de un decreto, por ejemplo, depende de la sujeción de este a las leyes vigentes, y la validez tanto de las leyes como de los decretos depende de la conformidad de unas y otros con la Constitución. La Constitución dentro de esta estructura jerárquica, es el criterio supremo de validez. ${ }^{16}$

El postulado teórico de Hart sobre la supremacía de la Constitución en un determinado ordenamiento o sistema jurídico es esencial, ya que el texto constitucional determina la estructura jurídica en conjunto y las leyes que estén en contravía de la Carta deben revisarse con detenimiento por las posibilidades de validez que otorga el documento constitucional. Así, la Constitución se convierte en un texto que posibilita la armonía dentro del ordenamiento jurídico y limita las leyes que la afecten negativamente:

[...] las ideas de regla última de reconocimiento, criterio supremo, y legislatura jurídicamente ilimitada, parecen convergir. Porque cuando hay una legislatura que no está sometida a limitaciones constitucionales, y tiene competencia para privar a todas las otras reglas emanadas de otras fuentes de su status jurídico, es parte de la regla de reconocimiento de tal sistema que la sanción de aquella legislatura constituye el criterio supremo de validez. Esta es, de acuerdo con la

16 César Rodríguez, "Teoría del Derecho y decisión judicial. En torno al debate entre H. L. A. Hart y Ronald Dworkin" en La decisión judicial. El debate Hart-Dworkin, ed. César Rodríguez (Bogotá: Universidad de los Andes, 2005), 27. 
teoría constitucional, la situación en el Reino Unido. Pero aun sistemas como el de los Estados Unidos, donde no existe tal legislatura jurídicamente ilimitada, pueden perfectamente bien contener una regla última de reconocimiento que proporciona un conjunto de criterios de validez, uno de los cuales es supremo. Ocurre esto cuando la competencia legislativa de la legislatura ordinaria está limitada por una constitución que no contiene la potestad de introducir enmiendas, o que coloca algunas cláusulas fuera del alcance de esa potestad, aquí no hay legislatura jurídicamente ilimitada, ni siquiera en la interpretación más amplia de "legislatura"; pero el sistema contiene, por supuesto, una regla última de reconocimiento y, en las cláusulas de la Constitución, un criterio supremo de validez. ${ }^{17}$

Los postulados teóricos de los profesores Kelsen y Hart convulsionaron al positivismo jurídico tradicional desde el mismo positivismo, ampliaron el horizonte teórico y se adaptaron a las transformaciones jurídicas que tocaron la teoría del derecho, el Derecho Constitucional y el Derecho Internacional. Tal incidencia llevó a que los paradigmas jurídicos fueran remplazados por otras perspectivas teóricas y prácticas y se retomaron los aportes de estos profesores a la Ciencia Jurídica y al Derecho. De esta forma, se convirtieron en los antecesores de los planteamientos del reciente neoconstitucionalismo.

\section{El neoconstitucionalismo como soporte teórico del Estado constitucional}

El neoconstitucionalismo pretende explicar el fenómeno de la Constitución como eje del Estado constitucional y democrático de Derecho, que se expresa por medio de los textos constitucionales incorporados recientemente por parte de los Estados contemporáneos. Esta corriente, propia del Derecho Constitucional, pretende considerar a la Constitución como texto de principios, derechos, valores y normas superiores que rigen la actuación del Estado con respecto a los ciudadanos:

Se trata de constituciones que no se limitan a establecer competencias o a separar a los poderes públicos, sino que contienen altos niveles de normas "materiales" o

${ }_{17}$ Herbert Hart, El concepto de Derecho (Buenos Aires: Abeledo-Perrot. 1963), 132-133. 
sustantivas que condicionan la actuación del Estado por medio de la ordenación de ciertos fines y objetivos. ${ }^{18}$

La importancia de esta teoría neoconstitucional ha ido creciendo desde Europa hacia América Latina, en donde se ha presentado una mayor influencia en los ordenamientos jurídicos de los Estados que son grandes focos culturales, jurídicos, políticos y económicos:

El neoconstitucionalismo [...] parece contar cada día con más seguidores, sobre todo en el ámbito de la cultura jurídica italiana y española, así como en diversos países de América Latina (particularmente en los grandes focos culturales de Argentina, Brasil, Colombia y México). ${ }^{19}$

La estructura jurídica de estos Estados se ha transformado por la pretensión de una Constitución efectiva que dinamice las instituciones estatales y le otorgue una mayor relevancia al Poder Judicial:

En el paradigma neoconstitucional los jueces cobran gran relevancia, pues el ordenamiento jurídico debe estar garantizado en todas sus partes por medio de mecanismos jurisdiccionales. Del mismo modo que la Constitución del neoconstitucionalismo es una Constitución "invasora" o "entrometida" (según la correcta observación de RICARDO GUASTINI), también la tarea judicial tiene que ver con muchos aspectos de la vida social. El neoconstitucionalismo genera una explosión de la actividad judicial y comporta o requiere de algún grado de activismo judicial, en buena medida superior al que se había observado antes. ${ }^{20}$

Con la relevancia que se les asigna a los jueces en el Estado constitucional, estos comienzan a ser una figura fundamental para el campo jurídico, pues sus decisiones fortalecen y consolidan la Constitución y se convierten en sus guardianes, protectores de derechos fundamentales y creadores de Derecho:

\footnotetext{
18 Miguel Carbonell, "El neoconstitucionalismo: significado y niveles de análisis" en El canon neoconstitucional, eds. Miguel Carbonell y Leonardo García Jaramillo (Bogotá: Universidad Externado de Colombia, 2010), 162.

19 Carbonell, "El neoconstitucionalismo", 161.

20 Carbonell, "El neoconstitucionalismo", 163.
} 
El juez nunca debe decir lo que el Derecho debe ser, de conformidad con su ideología, sino lo que el Derecho es, según una interpretación general de la Constitución y de la moral política que mediante esta última se institucionaliza [...] la Corte Constitucional es un auténtico poder para crear nuevas normas. Las normas que se adscriben dentro de los márgenes semánticos de dichas cláusulas, las subreglas, como las denomina la jurisprudencia y un sector de la doctrina, no constituyen una emanación directa del contenido de los derechos fundamentales, sino una creación original del juez constitucional. ${ }^{21}$

Desde la perspectiva neoconstitucional, las decisiones judiciales son de un carácter más amplio y no se limitan al estricto seguimiento de la ley. La referencia de principios en estas decisiones determinan una transformación jurídica que supera lo normativo — postulado argumentado por Dworkin—, con la concepción innovadora de que los principios interpretados por los jueces resuelven problemas jurídicos. Esto lleva a que toda decisión judicial deba apoyarse en principios, ya que el Derecho no solo se conforma por normas, sino también por pretensiones generales o principios que pueden resolver casos concretos:

En realidad, lo que quiero es oponerme a la idea de que el Derecho sea un conjunto fijo de estándares, de la clase que sean. Más bien insisto en que un resumen preciso de las consideraciones que deben tener en cuenta los abogados y jueces, cuando justifican sus conclusiones, usan frecuentemente proposiciones que han de ser entendidas de esa manera. ${ }^{22}$

\section{Garantismo, argumentación jurídica y Estado constitucional}

El garantismo, teoría que tiene entre sus representantes destacados al jurista Luigi Ferrajoli, parte de la conceptualización de los derechos fundamentales, que se vincula con el concepto de constitucionalismo, democracia y Estado constitucional:

La propuesta teórica de Ferrajoli relativa a los derechos fundamentales se inscribe, por un lado, en la teoría formalizada del Derecho en cuya elaboración y perfeccionamiento el autor trabaja desde hace muchos años [...] también esta largamente elaborada, sobre el significado esencial del constitucionalismo y del "garantismo", o bien, de la que Ferrajoli llama "democracia constitucional",

\footnotetext{
Carlos Bernal Pulido, El Derecho de los derechos (Bogotá: Universidad Externado de Colombia, 2005), 18. 22 Ronald Dworkin, Los derechos en serio (Barcelona: Ariel, 2002), 140.
} 
entendida como "un complejo sistema de reglas, vínculos y equilibrios" que incluye "al parlamentarismo y, también al Estado social, la división de poderes y, también, la garantía de los derechos". 23

El garantismo es determinante y predominante en el Estado constitucional y democrático de Derecho, ya que, para Ferrajoli, en este modelo los derechos deben de garantizarse. Desde esta perspectiva, las obligaciones de las instituciones estatales consisten en crear garantías necesarias para la materialización de los derechos. En este contexto, el Estado debe de garantizar los derechos a sus asociados de forma concreta y precisa, por medio de políticas y acciones gubernamentales de carácter económico y social, para que no sean derechos que se limitan al papel, a los escritos y la publicidad:

[...] los derechos exigen garantías idóneas, que deben ser establecidas y hechas valer eficazmente por el mismo ordenamiento normativo que atribuyen los derechos. Desde este punto de vista, la existencia de "derechos sin garantías" parece una especie de aporía dentro de un ordenamiento, que, por un lado, crea expectativas normativas, y, por otro, las ignora (o no las satisface adecuadamente) [...]. Paradójicamente, en la mayoría de los ordenamientos contemporáneos son identificables como derechos sin (idóneas) garantías algunos de los derechos que pertenecen a su clase más importante: la de los derechos fundamentales. ${ }^{24}$

Para el jurista italiano, la garantía en el Estado constitucional se divide en primaria y secundaria. Estos dos tipos vinculan al parlamento y al juez como actores predominantes al momento de ejecutarlas:

Si es verdad, en efecto, que en los ordenamientos dotados de Constitución rígida existe una obligación del juez constitucional de anular las normas que sean constitucionalmente inválidas (lo que he denominado "garantía secundaria") y que a las expectativas positivas, como las de los derechos sociales, les corresponde la obligación de satisfacerlas con leyes de desarrollo adecuadas (lo que he denominado "garantía primaria"). ${ }^{25}$

23 Michelangelo Bovero, "Derechos fundamentales y democracia en la teoría de Ferrajoli. Un acuerdo global y una discrepancia concreta" en Los fundamentos de los derechos fundamentales, Luigi Ferrajoli (Madrid, Trotta, 2005), 216

24 Bovero. "Derechos fundamentales y democracia en la teoría de Ferrajoli", 227.

25 Luigi Ferrajoli, Garantismo: una discusión sobre Derecho y democracia (Madrid: Trotta, 2009), 75-76. 
La garantía de los derechos fundamentales se realiza primero en el Estado social con los derechos sociales y luego en el Estado constitucional y democrático de Derecho, en el que se supone que los derechos deben estar garantizados, ya que el deber no es garantizar, sino proteger. Esto no ocurre en los Estados constitucionales contemporáneos, en los que los derechos fundamentales no son garantizados, situación que impulsa a que los ciudadanos acudan a los estrados judiciales para que no sean vulnerados por parte de las instituciones estatales. Por eso, para Ferrajoli, el Estado constitucional debe adecuarse a una particular concepción de democracia, la cual se sustenta en los derechos fundamentales. A esto lo ha señalado como democracia sustancial:

Ninguna mayoría política puede disponer de las libertades y de los demás derechos fundamentales: decidir que una persona sea condenada sin pruebas, privada de la libertad personal, de los derechos civiles o políticos o, incluso dejada morir sin atención o en la indigencia. De aquí la connotación de "sustancial" impresa por los derechos fundamentales al Estado de Derecho y a la democracia constitucional. En efecto, las normas que adscriben —más allá e incluso contra las voluntades contingentes de las mayorías - los derechos fundamentales: tanto los de libertad que imponen prohibiciones, como los sociales que imponen obligaciones al legislador, son "sustanciales", precisamente por ser relativas no a la "forma" (al quien y al cómo) sino a la "sustancia" o "contenido" (al qué) de las decisiones (o sea, al que no es lícito decidir o no decidir). Resulta así desmentida la concepción corriente de la democracia como sistema político fundado en una serie de reglas que aseguran la omnipotencia de la mayoría. Si las reglas sobre la representación y sobre el principio de las mayorías son normas formales en orden a lo que es decidible por la mayoría, los derechos fundamentales circunscriben la que podemos llamar esfera de lo indecidible: de lo no decidible que, es decir, de las prohibiciones determinadas por los derechos de libertad, y de lo no decidible que no, es decir, de las obligaciones públicas determinadas por los derechos sociales. ${ }^{26}$

En el Estado constitucional y democrático de Derecho, no es suficiente la garantía de los derechos fundamentales, pese a que esta se ha convertido en una de las acciones principales de este modelo de Estado. También es cierto que a las instituciones públicas les nace una nueva obligación y es la de fundamentar sus decisiones en los límites y parámetros constitucionales. Desde esta perspectiva, la capacidad

26 Ferrajoli, Los fundamentos de los derechos fundamentales, 36. 
argumentativa de las instituciones públicas —en especial de aquellas que protegen los derechos fundamentales, como la institución judicial - cobra una mayor relevancia y, por lo tanto, una mayor complejidad, pues tiene que suplir los vacíos y las ambigüedades normativas por medio de sus jurisprudencias. En este marco, la teoría de la argumentación jurídica, del profesor Robert Alexy, es importante por los elementos que brinda al proceso de argumentación por parte de los jueces y las instituciones estatales en el cumplimiento de sus obligaciones, que se encuentran respaldadas por el discurso jurídico:

La argumentación jurídica se concibe a tal efecto como una actividad lingüística que tiene lugar en situaciones tan diferentes como, por ejemplo el proceso y la discusión científico-jurídica. De lo que se trata en esta actividad lingüística es de la corrección de los enunciados normativos, en un sentido todavía por precisar. Será conveniente designar tal actividad como "discurso" y, puesto que se trata de la corrección de enunciados normativos, como "discurso práctico". El discurso jurídico es un caso especial del discurso práctico general. ${ }^{27}$

En esta teoría del Derecho, el juez es esencial, ya que es el intérprete legítimo de la Constitución y tiene como responsabilidad resolver las disputas jurídicas relacionadas con la protección de los derechos. Por ello, para la teoría de la argumentación jurídica, las decisiones judiciales deben tener un alto contenido argumentativo que, en parte, pueden obtenerlo del precedente:

Una teoría de la argumentación jurídica que no diera cuenta del papel de los precedentes omitiría uno de los aspectos esenciales de la argumentación jurídica [...] el fundamento del uso de los precedentes lo constituye el principio de universalidad, la exigencia subyace a toda concepción de la justicia, en cuanto a concepción formal, de tratar de igual manera a lo igual [...] es posible que un caso sea igual a otro caso anteriormente decidido en todas las circunstancias relevantes, pero que sin embargo se debe decidir de otra manera porque entre tanto, ha cambiado la valoración de estas circunstancias. ${ }^{28}$

El Derecho Constitucional ha configurado teorías críticas al modelo de Estado constitucional y democrático de derecho, que señalan el excesivo protagonismo

27 Robert Alexy, Teoría de la argumentación jurídica (Madrid: Centro de Estudios Políticos y Constitucionales, 2012), 34.

28 Alexy, Teoría de la argumentación jurídica, 261-263. 
de los jueces constitucionales, la concepción de democracia y el control de constitucionalidad que distingue a este modelo:

Sin embargo, la dificultad de atacar este modelo radica en que, después de la Segunda Guerra Mundial, se percibe que la "evolución" del Estado de Derecho es un "progreso" hacia la consolidación del juez constitucional como el operador jurídico que cierra las discusiones sobre el significado de la Constitución en las democracias contemporáneas. ${ }^{29}$

Estas reflexiones constitucionales no se limitan a la crítica: también se adelantan propuestas que tienen la pretensión de recuperar la participación directa de los ciudadanos en las decisiones que les afectan, ya que el control constitucional no debe ser exclusivo de los jueces, sino que además deben ejercerlo los ciudadanos. Los teóricos lo han denominado constitucionalismo popular:

El punto de partida de los constitucionalistas populares es que el excesivo poder de los jueces en las democracias contemporáneas les quita poder a los ciudadanos comunes y corrientes, y menosprecia los principios de democracia participativa e igualdad, que deben guiar las decisiones políticas más importantes dentro de una comunidad. ${ }^{30}$

En muchos países latinoamericanos, el neoconstitucionalismo se ha quedado en una simple propuesta filosófica con pocos efectos en esta compleja realidad. Por esta razón, en América Latina se ha pretendido implementar una propuesta innovadora: el nuevo constitucionalismo latinoamericano, propuesta que puede tener una mayor influencia práctica y transformar la realidad para beneficio de los ciudadanos de la región:

El concepto nuevo constitucionalismo es aún más reciente que el neoconstitucionalismo. A diferencia del neoconstitucionalismo, que surge desde la filosofía del Derecho y desea trascender a la práctica jurisprudencial, el nuevo constitucionalismo tiene un doble objetivo. Por un lado, recuperar y actualizar el concepto de poder constituyente democrático, garantizando el origen democrático de la Constitución a través de una iniciativa popular de activación del mismo y del ejercicio de dicho poder fundante mediante una asamblea constituyente

\footnotetext{
Erwin Chemerinsky y Richard Parker, Constitucionalismo popular (Bogotá: Siglo del Hombre, 2011), 31.

30 Chemerinsky y Parker, Constitucionalismo popular, 31 .
} 
participativa y plural, así como la conveniente aprobación directa de la Constitución por la ciudadanía a través de una consulta popular. Por otro lado, generar unos contenidos constitucionales que permitan resolver los problemas de legitimidad del sistema que el constitucionalismo social de origen europeo no ha conseguido solventar. ${ }^{31}$

De esta forma, se vuelve imprescindible la búsqueda de factores que suplan las falencias de la propuesta teórica del neoconstitucionalismo. Si se observa en los teóricos que se oponen o critican esta teoría se encuentran - tanto en Estados Unidos, con el constitucionalismo popular, como en los Estados latinoamericanos, con el nuevo constitucionalismo- propuestas teóricas con una pretensión similar, enfocadas en vincular directamente a la ciudadanía en la construcción del Estado. Es importante reconocer que el neoconstitucionalismo trajo consigo novedosas ideas que ya se han desarrollado en este trabajo, pero también se debe admitir el papel fundamental de la ciudadanía en la construcción de un nuevo modelo estatal que garantice, de una forma eficaz, los derechos fundamentales, ejerza un adecuado control de constitucionalidad y, no menos importante, que sea partícipe en la construcción de una Constitución vinculante y pluralista.

\section{La influencia y los obstáculos del Estado constitucional en Colombia}

El neoconstitucionalismo ha tenido una implementación tímida y paulatina en el país, que amplía las perspectivas de la teoría del Derecho y la práctica jurídica y tiene su mayor representación en el reciente modelo estatal conocido como Estado constitucional y democrático de Derecho. En este proceso de implementación estatal, se ha hecho imprescindible el papel de la Corte Constitucional, la cual ha adoptado una posición vanguardista, pluralista e incluyente, por medio de su jurisprudencia, en la que expone la defensa y el cumplimiento de los derechos y principios constitucionales en beneficio de los ciudadanos.

En sus pronunciamientos, la Corte Constitucional ha determinado la supremacía constitucional y del juez como creador de Derecho desde los derechos fundamentales, al aceptar un modelo estatal que tiene como privilegio la Constitución y la

31 Roberto Viciano Pastor y Rubén Martínez Dalmau, "La Constitución democrática entre el neoconstitucionalismo y el nuevo constitucionalismo", El otro Derecho núm. 48 (2013): 71-72. 
responsabilidad institucional de garantizar y proteger los derechos de los ciudadanos, concepciones que caracterizan al Estado constitucional:

La acepción Estado de Derecho se refiere a que la actividad del Estado está regida por las normas jurídicas, es decir que se ciñe al Derecho. La norma jurídica fundamental es la Constitución, lo cual implica que toda la actividad del Estado debe realizarse dentro del marco de la última. En esta situación se habla entonces de Estado constitucional de Derecho. ${ }^{32}$

Los jueces han transformado su concepción tradicional del Derecho, ya que su práctica no se limita a seguir postulados normativos y hacen complejos análisis argumentativos y lógicos, en los cuales incorporan los principios constitucionales y las teorías del Derecho como la argumentación jurídica:

[...] el Derecho no es una aplicación mecánica de consecuencias jurídicas previstas en preceptos generales, como lo aspiraba la práctica jurídica de inicios del siglo XIX, marcada por el concepto del Código, sino una práctica argumentativa racional. Además, este último argumento permite hacer compatible la actividad creadora de Derecho por parte de los jueces con el principio democrático. ${ }^{33}$

Para la implementación parcial de este modelo de Estado, no solo fue esencial la Corte Constitucional, pues las universidades de élite también han desempeñado un destacado papel en el avance del modelo desde las publicaciones jurídicas en las que se amplía la teoría del Derecho, ya que se introducen al país textos con postulados innovadores, diferentes al legalismo y formalismo jurídico. Esto se propició por medio de obras propias o traducciones de autores extranjeros, lo que llevó a conocer teóricos con ideas importantes que transformaron la cultura jurídica del país. Se destacan autores como Ronald Dworkin, Hebert Hart y Robert Alexy, entre otros, con ideas progresistas para un entorno un poco conservador como el colombiano:

Este marco permite asimismo entender que a partir tanto de las lecturas y renovadas interpretaciones de textos jurídicos cuyos autores eran bien conocidos en el exterior pero prácticamente anónimos hasta ese momento en nuestro contexto, como de la propia producción bibliográfica nacional —original y

Corte Constitucional, Sentencia SU-747 de 2 de diciembre de 1998, M. P. Eduardo Cifuentes Muñoz. Corte Constitucional, Sentencia C-634 de 24 de agosto de 2011, M. P. Luis Ernesto Vargas Silva. 
por traducciones—, empezó a difundirse y a arraigarse cada vez más una serie de nuevos elementos de análisis jurídico, argumentos de índole constitucional y mecanismos para la interpretación y aplicación de las provisiones constitucionales originadas en otras jurisdicciones (como la estadounidense y la alemana) así como ideologías de raigambre antiformalista y antitradicional que enderezaban críticas a la cultura jurídica dominante. ${ }^{34}$

Estas concepciones han pretendido transformar el Derecho como disciplina científica y como práctica, en concordancia con las características del Estado constitucional y democrático de Derecho que se plasman tímidamente en la Constitución de 1991, al romper con las reglas que predominaron durante un siglo con la Constitución de 1886. En esta última, la ley y el formalismo jurídico eran centrales para este tipo de ordenamiento jurídico, en el que los creadores de la ley, que eran las instituciones políticas del Estado como el Ejecutivo y el Legislador, se convirtieron en actores principales:

Dichos elementos se relacionan, esencialmente, con la interpretación y aplicación del Derecho, la reformulación de nuestro sistema de fuentes y el subsiguiente descenso de la ley del sitial que ocupaba en el podio de las fuentes del Derecho, el papel del juez constitucional en la creación y desarrollo del Derecho, la legitimidad de la justicia constitucional, la relación entre Derecho y la sociedad, el carácter vinculante de los principios, la consideración de la fundamentalidad de los derechos sociales y la procura de su justiciabilidad judicial, entre otros. ${ }^{35}$

La implementación del modelo de Estado constitucional ha sido compleja. Los obstáculos que imposibilitan una buena ejecución de las pretensiones de este modelo estatal aparecen constantemente, debido a los intereses de ciertas élites políticas y económicas que no comparten el excesivo control que ejercen los jueces constitucionales sobre sus decisiones y la defensa permanente de los derechos fundamentales que protegen a los ciudadanos. Desde una perspectiva liberal, este modelo estatal es una propuesta satisfactoria y de avanzada, ya que transformaría a los Estados en una organización que, de forma permanente, estaría preocupado por el bienestar de sus ciudadanos, no con base en la lógica teórica, sino en un

\footnotetext{
34 Leonardo García Jaramillo, "El neoconstitucionalismo en Colombia: ¿entelequia innecesaria o novedad pertinente?" en El canon neoconstitucional, eds. Miguel Carbonell y Leonardo García Jaramillo (Bogotá: Universidad Externado de Colombia, 2010), 330.

35 García Jaramillo, "El neoconstitucionalismo en Colombia", 330.
} 
aspecto material; sin embargo, estas pretensiones no han podido llevarse a cabo en el contexto colombiano:

Los Estados tienen éxito o fracasan en algunas o en todas estas dimensiones. Pero lo que permite distinguir a los Estados fuertes de los débiles y a los Estados débiles de aquellos que fracasan o colapsan en su desempeño en relación con los niveles de suministro efectivo de los bienes políticos más fundamentales. Los bienes políticos son aquellas solicitudes intangibles y difíciles de cuantificar que en su tiempo hacían los ciudadanos a los soberanos y que hoy presentan a los Estados. Comprenden expectativas locales, es decir, las obligaciones concebibles; inspiran la cultura política social y, en conjunto, dan contenido al contrato social entre gobernantes y gobernados que se encuentran en el corazón de las interacciones entre régimen o gobierno y ciudadanía. ${ }^{36}$

\section{Conclusión}

Entre las dificultades que se han presentado en la implementación del modelo estatal analizado en el contexto colombiano se encuentra el cumplimiento de los derechos fundamentales, que son esenciales para ejercer una ciudadanía plena. Entre los ejemplos está la vulneración permanente del derecho a la salud, pues para evitar que se vea afectada con gravedad, los ciudadanos acuden a la acción de tutela, situación recurrente en el país.

Ante el incumplimiento de los derechos sociales fundamentales en el Estado social de Derecho por parte de las instituciones públicas responsables, el paso al Estado constitucional y democrático de Derecho no ha podido hacerse en el contexto colombiano y en varios Estados latinoamericanos, porque no se pueden proteger derechos fundamentales que ni siquiera se han logrado garantizar. Frente a tal situación de dificultad, algunos Gobiernos de la región han impulsado la creación de modelos estatales propios, más cercanos a la realidad. La pretensión de crear modelos de Estado propios se ha venido configurando en países de la región como Ecuador y Bolivia que, por medio de la promulgación de Constituciones con una amplia participación ciudadana, han adecuado derechos y principios más cercanos a su realidad indígena. Así, en la Constitución ecuatoriana de 2008 y en la boliviana

Robert I. Rotberg, "El fracaso y el colapso de los Estados Nación. Descomposición, prevención y reparación" en Los Estados fallidos o fracasados: un debate inconcluso y sospechoso, ed. Patricia Moncada Roa (Bogotá: Siglo del Hombre Editores, Universidad de los Andes, Pontificia Universidad Javeriana, 2007), 157. 
de 2009, se determinaron como Estados plurinacionales que reconocían, en el caso de Ecuador, las tradiciones de la Pacha Mama que protegen los recursos naturales y la participación indígena en la política y lo jurídico, por medio de movimientos indígenas en los espacios de decisión, así como la creación del primer tribunal indígena en la región.

\section{Referencias}

Aguiló, Josep. La Constitución del Estado constitucional. Bogotá: Temis, 2004.

Alexy, Robert. Teoría de la argumentación jurídica. Madrid: Centro de Estudios Políticos y Constitucionales, 2012.

Bernal Pulido, Carlos. El Derecho de los derechos. Bogotá: Universidad Externado de Colombia, 2005.

Bernal Pulido, Carlos. "Derechos fundamentales, juristocracia constitucional e hiperpresidencialismo en América Latina" en Justica constitucional, derechos humanos y democracia en América Latina, dirigido por Martin Arnaud, 31-62. Bogotá: Universidad Externado de Colombia, 2014.

Bovero, Michelangelo. "Derechos fundamentales y democracia en la teoría de Ferrajoli. Un acuerdo global y una discrepancia concreta" en Los fundamentos de los derechos fundamentales, Luigi Ferrajoli, 215-242. Madrid, Trotta, 2005.

Carbonell, Miguel. "El neoconstitucionalismo: significado y niveles de análisis" en El canon neoconstitucional, editado por Miguel Carbonell y Leonardo García Jaramillo, 159-171. Bogotá: Universidad Externado de Colombia, 2010.

Chemerinsky, Erwin y Richard Parker. Constitucionalismo popular. Bogotá: Siglo del Hombre, 2011.

Córdova Vianello, Lorenzo. Derecho y poder: Kelsen y Schmitt frente a frente. México D. F: Universidad Nacional Autónoma de México, 2009.

Corte Constitucional. Sentencia SU-747 de 2 de diciembre de 1998. M. P. Eduardo Cifuentes Muñoz.

Corte Constitucional. Sentencia C-634 de 24 de agosto de 2011. M. P. Luis Ernesto Vargas Silva.

Dworkin, Ronald. Los derechos en serio. Barcelona: Ariel, 2002.

Ferrajoli, Luigi. Los fundamentos de los derechos fundamentales. Madrid: Trotta, 2005.

Ferrajoli, Luigi. Garantismo: una discusión sobre Derecho y democracia. Madrid: Trotta, 2009. 
García Jaramillo, Leonardo. "El neoconstitucionalismo en Colombia: ¿entelequia innecesaria o novedad pertinente?" en El canon neoconstitucional, editado por Miguel Carbonell y Leonardo García Jaramillo. Bogotá: Universidad Externado de Colombia, 2010.

Haberle, Peter. Constitución como cultura. Bogotá: Universidad Externado de Colombia, 2002. Hart, Herbert. El concepto de Derecho. Buenos Aires: Abeledo-Perrot. 1963.

López Mediana, Diego Eduardo. Teoría impura del Derecho. La transformación de la cultura jurídica latinoamericana. Bogotá: Universidad de los Andes, 2004.

Peña Freire, Antonio. La garantía en el Estado constitucional de Derecho. Madrid: Trotta, 1997.

Quince Ramírez, Manuel Fernando. Derecho constitucional colombiano de la Carta de 1991 y sus reformas. Bogotá: Universidad del Rosario, 2009.

Rodríguez, César. "Teoría del Derecho y decisión judicial. En torno al debate entre H. L. A. Hart y Ronald Dworkin" en La decisión judicial. El debate Hart-Dworkin, editado por César Rodríguez, 15-88. Bogotá: Universidad de los Andes, 2005.

Rotberg, Robert I. "El fracaso y el colapso de los Estados Nación. Descomposición, prevención y reparación" en Los Estados fallidos o fracasados: un debate inconcluso y sospechoso, editado por Patricia Moncada Roa, 151-237. Estudio preliminar. Bogotá: Siglo del Hombre Editores, Universidad de los Andes, Pontificia Universidad Javeriana, 2007.

Stone Sweet, Alec y Jud Matthews. Proporcionalidad y constitucionalismo. Un enfoque comparativo global. Bogotá: Universidad Externado de Colombia, 2013.

Viciano Pastor, Roberto y Rubén Dalmau Martínez. "La Constitución democrática, entre el neoconstitucionalismo y el nuevo constitucionalismo”. El otro Derecho, núm. 48 (2013): 63-84. 